\title{
MTA versus CEM root-end fillings effect on fracture resistance of endodontically treated simulated immature teeth restored with cast metal posts: an in-vitro study
}

\section{Ensieh Grayli}

Golestan University of Medical Sciences

Abbas Dashtban

Golestan University of Medical Sciences

\section{Leyla Shadan}

Golestan University of Medical Sciences

Naser Behnampour

Golestan University of Medical Sciences

Elham Afshari ( $\nabla$ dr.afshari@goums.ac.ir)

Golestan University of Medical Sciences

\section{Research Article}

Keywords: Fracture resistance, cast metal, endodontic post, bioceramics, MTA, CEM

Posted Date: March 12th, 2021

DOI: https://doi.org/10.21203/rs.3.rs-189967/v1

License: (c) (1) This work is licensed under a Creative Commons Attribution 4.0 International License.

Read Full License 


\section{Abstract}

Background: Endodontically treated immature teeth which are restored with cast metal posts are of the most susceptible teeth to fracture. An apical plug is usually used as root end filling in order to seal the wide apical foramen. The current study was performed to evaluate the effect of different root-end filling materials (MTA and CEM) on fracture resistance of teeth restored with cast metal posts.

Methods: A total of 40 extracted intact single-rooted human mandibular premolars (removed for orthodontic reasons) were used in the study. The coronal part of each tooth was removed and root canal preparation was performed. A size 4 Gates Glidden drill was used to enlarge the canal and was passed through the apical foramen in order to simulate an immature apex. Samples were randomly divided into 5 groups according to apical plug (Group 1: No plug, Group 2: $5 \mathrm{~mm}$ MTA plug, Group 3: $5 \mathrm{~mm}$ CEM plug, Group 4: 2 mm MTA plug, Group 5: 2 mm CEM plug). Post-space preparations were performed and cast metal post-and-cores were fabricated and cemented. Fracture resistance was assessed using a universal testing machine. Fracture thresholds were recorded and data were analyzed using SPSS 16.0 with significance level at $P$ value $<0.05$.

Results The analysis showed a significant difference of fracture resistance between groups ( $\mathrm{p}$ value $<0.05$ ). The mean fracture resistance of samples in group 1 was significantly lower than group 2 ( $p$ value $=0.003$ ). there was no significant difference between other groups ( $p$-value $>0.05$ ).

\section{Conclusions:}

Within the limits of this study, the evidence indicated that placement of a $5 \mathrm{~mm}$ MTA apical plug increased the fracture resistance in simulated immature teeth which are restored with cast metal posts, compared to control group (gutta-percha and sealer). While the results were not as promising for a $2 \mathrm{~mm}$ MTA apical plug or either 2 or $5 \mathrm{~mm}$ CEM apical plug.

\section{Background}

Endodontic and prosthodontic treatment of immature teeth has always been challenging for practitioners. All the three factors of being endodontically treated (apexification), immaturity, and being restored with cast metal post, are among risk factors for root fracture. (1-4) Therefore, endodontically treated immature teeth which are restored with cast metal posts are of the most susceptible teeth to fracture.

Achieving an appropriate apical seal which is essential for prevention of microorganism's ingress, is challenging in immature teeth, due to the wide apical foramen. $(5,6)$ Different materials have been advocated for root-end filling, among which bioceramic-based materials such as Mineral trioxide aggregate (MTA), BioAggregate, Biodentine, Calcium enriched mixture cement (CEM) are of the most popular materials. (7) The use of bioceramic-based materials has shown to decrease the fracture 
susceptibility compared to calcium hydroxide paste which was traditionally used for endodontic treatment of immature teeth before introduction of bioceramic-based materials. $(4,8,9)$

If an endodontically treated tooth is severely damaged, restoration of the tooth structure usually requires a post-and-core system. Currently, there are several post or post and-core systems available using different materials and techniques such as metal cast posts, metal prefabricated posts, carbon fiber posts, glass fiber posts, and zirconia posts. $(10,11)$

Despite better esthetic results of recently developed posts such as glass fiber posts, and zirconia posts $(10,12)$, cast metal post-and-core systems have been a successful treatment option for the restoration of severely damaged endodontically treated teeth -especially posterior teeth $(13,14)$

To the best of our knowledge, this is the first study to evaluate the effect of different root-end filling materials (MTA and CEM) on fracture resistance of teeth restored with cast metal posts.

\section{Methods}

A total of 40 extracted intact single-rooted human mandibular premolars (removed for orthodontic reasons in dental clinic of Gorgan School of Dentistry and three private offices) were selected based on the inclusion criteria. The teeth were disinfected with $5.25 \% \mathrm{NaOCl}$ and stored in isotonic saline solution. Visual and microscopic (stereomicroscope at 10x magnification) assessments were performed and teeth with a single straight root of similar length and size with no sign of crack, fracture, or carious lesion were selected. The coronal part of each tooth was removed in a way that a $16 \mathrm{~mm}$ root was remained.

Root canal preparation was performed using rotary NiTi Protaper instruments (DentsplyMaillefer, Ballaigues, Switzerland) with shaping and finishing files (Sx, S1, S2, F1 and F2). Canals were irrigated with $2 \mathrm{ml}$ isotonic saline between preparation steps. A size 4 Gates Glidden drill was used to enlarge the canal and was passed through the apical foramen in order to simulate an immature apex. Samples were randomly divided into 5 groups (a control group and 4 experimental groups) according to root root-end filling material [mineral trioxide aggregate (MTA Angelus, Soluçoes Odontologicas, Londrina, Brazil), and (calcium enriched mixture (CEM, BioniqueDent, Tehran, Iran)]

- Group 1 (control): No plug

- Group 2: MTA orthograde $5 \mathrm{~mm}$ plug

- Group 3: CEM orthograde $5 \mathrm{~mm}$ plug

- Group 4: MTA orthograde $2 \mathrm{~mm}$ plug

- Group 5: CEM orthograde $2 \mathrm{~mm}$ plug

In groups 2-4, root-end filling materials (MTA or CEM) were condensed using paper points. Correct placement was confirmed with radiographs. A wet paper point was placed in the root canal and samples were stored in wet gauze for 24 hours. All root canals were obturated using gutta-percha (Meta Biomed 
Co. Ltd, Korea) and AH26 sealer (Dentsply, DeTrey, Germany) using the lateral condensation technique and incubated for 1 week at $37^{\circ} \mathrm{C}$.

The roots were then mounted in self-curing resin blocks. samples were vertically stabilized on surveyor, using plastic cylinders filled with acrylic resin. Post-space preparations were performed using preparation drills (D.T. Light-Post Universal Drill Size \#0.5 for filling removal and D.T. Light-Post Finishing Drill Size \#1 for post-space shaping). A minimum of $5 \mathrm{~mm}$ of apical seal was retained in all groups.

Resin patterns of posts were fabricated using acrylic resin (Duralay, Reliance Dental Mfg. Co., worth, Illinois) and direct technique. A 4-mm-height resin pattern for core was fabricated for all samples. Patterns were spurred, invested ((Deguvest Impuls, Degu Dent Co., Germany), and casted using Ni-Cr alloy (T-3 Ni-Cr, CMP Industries LLC, NY, USA).

The castings were cleaned, sandblasted, and adjusted into the root canal. The castings were cemented with resin luting cement (Panavia F2.0, Kuraray medical Inc., OsaKa, Japan), using finger pressure.

Fracture resistance was assessed using a universal testing machine (Zwik/ Roell 020, Ulm, Germany). A static load was applied to each sample with a $90^{\circ}$ angle to the occlusal surface of the metal core at a crosshead speed of $0.05 \mathrm{~cm} / \mathrm{min}$ until the fracture occurred. Fracture thresholds were recorded and data were analyzed using SPSS 16.0 with significance level at $P$ value $<0.05$.

\section{Results}

The current study was conducted on 40 extracted teeth in 5 groups. The mean, standard deviation, minimum, and maximum fracture resistance for each group is presented in table 1.

Table 1: Fracture resistance of teeth in 5 groups

\begin{tabular}{|llllll|}
\hline Groups & N & Mean & Std. Deviation & Minimum & Maximum \\
\hline 1 & 8 & 1582.638 & 460.6348 & 1183.3 & 2256.3 \\
\hline 2 & 8 & 2916.950 & 637.5956 & 1925.2 & 3740.1 \\
\hline 3 & 8 & 2200.775 & 367.2977 & 1630.9 & 2906.2 \\
\hline 4 & 8 & 2105.438 & 228.4752 & 1802.6 & 2405.3 \\
\hline 5 & 8 & 2259.363 & 542.7525 & 1440.8 & 2900.1 \\
\hline Total & 40 & 2213.033 & 619.2837 & 1183.3 & 3740.1 \\
\hline
\end{tabular}

The analysis showed a significant difference of fracture resistance between groups ( $p$-value<0.05). The mean fracture resistance of samples in group 1 was significantly lower than group 2 ( $p$-value=0.003). there was no significant difference between other groups ( $p$-value>0.05) (table 2). 
Table 2: Comparison of the fracture resistance of teeth in 5 groups

\begin{tabular}{|c|c|c|c|c|c|c|}
\hline \multicolumn{2}{|c|}{ Comparing groups } & \multirow[t]{2}{*}{ Mean Difference } & \multirow[t]{2}{*}{ Std. Error } & \multirow[t]{2}{*}{ p-value. } & \multicolumn{2}{|c|}{ 95\% Confidence Interval } \\
\hline & & & & & Lower Bound & Upper Bound \\
\hline \multirow[t]{4}{*}{ Group 1} & Group 2 & -1334.3125 & 278.0990 & .003 & -2254.889 & -413.736 \\
\hline & Group 3 & -618.1375 & 208.2943 & .089 & -1302.462 & 66.187 \\
\hline & Group 4 & -522.8000 & 181.7915 & .125 & -1149.867 & 104.267 \\
\hline & Group 5 & -676.7250 & 251.6855 & .145 & -1500.674 & 147.224 \\
\hline \multirow[t]{4}{*}{ Group 2} & Group 1 & 1334.3125 & 278.0990 & .003 & 413.736 & 2254.889 \\
\hline & Group 3 & 716.1750 & 260.1528 & .144 & -165.501 & 1597.851 \\
\hline & Group 4 & 811.5125 & 239.4601 & .066 & -44.383 & 1667.408 \\
\hline & Group 5 & 657.5875 & 296.0381 & .313 & -311.419 & 1626.594 \\
\hline \multirow[t]{4}{*}{ Group 3} & Group 1 & 618.1375 & 208.2943 & .089 & -66.187 & 1302.462 \\
\hline & Group 2 & -716.1750 & 260.1528 & .144 & -1597.851 & 165.501 \\
\hline & Group 4 & 95.3375 & 152.9332 & .999 & -418.494 & 609.169 \\
\hline & Group 5 & -58.5875 & 231.7024 & 1.000 & -830.257 & 713.082 \\
\hline \multirow[t]{4}{*}{ Group 4} & Group 1 & 522.8000 & 181.7915 & .125 & -104.267 & 1149.867 \\
\hline & Group 2 & -811.5125 & 239.4601 & .066 & -1667.408 & 44.383 \\
\hline & Group 3 & -95.3375 & 152.9332 & .999 & -609.169 & 418.494 \\
\hline & Group 5 & -153.9250 & 208.2010 & .995 & -885.770 & 577.920 \\
\hline \multirow[t]{4}{*}{ Group 5} & Group 1 & 676.7250 & 251.6855 & .145 & -147.224 & 1500.674 \\
\hline & Group 2 & -657.5875 & 296.0381 & .313 & -1626.594 & 311.419 \\
\hline & Group 3 & 58.5875 & 231.7024 & 1.000 & -713.082 & 830.257 \\
\hline & Group 4 & 153.9250 & 208.2010 & .995 & -577.920 & 885.770 \\
\hline
\end{tabular}

\section{Discussion}

While endodontic treatment by itself increases the risk of root fracture (1), immature endodontically treated teeth are at an even higher risk of root fracture because of their thin dentinal walls $(4,5)$. The situation becomes more complicated, if placement of an endodontic post is the treatment plan.

Although recently developed posts such as zirconia posts, carbon posts and glass fiber posts have offered better esthetic results than cast metal posts $(5,15)$, the superiority of success rate is controversial. 
Some studies have reported reduced chair-side and laboratory time of the new post systems $(10,12,15)$, while others reported the advantages of cast metal posts such as higher retention (14) or superiority of results in special circumstances such as when multiple teeth need post systems or in case of tooth malalignment, and in small teeth with minimal dental tissue. (16) Overall, cast metal posts are still one of the most used systems, especially for the posterior teeth. (17-18).

In the present study, the effect of type and thickness of root-end fillings (MTA vs CEM/ $2 \mathrm{~mm}$ vs $5 \mathrm{~mm}$ ) on fracture resistance of endodontically treated immature teeth restored with cast metal posts was assessed. Several studies have shown that a full canal obturation or an apical plugging by bio-ceramics, increases the fracture resistance of either mature or simulated immature teeth compared to the roots which were instrumented but were not filled, or were filled only with gutta-percha and sealer. $(8,19,20)$ Full canal obturation by bio-ceramics is not indicated when placement of an endodontic post is the treatment plan, because further removal of the material for post-space preparation might not be easy (21), and also the material is more expensive than gutta-percha and sealer. Therefore, in such cases, MTA or CEM are used as apical plugs and the rest of the root canal is filled with gutta-percha and sealer. $(22,23)$

The results of the current study showed that the fracture resistance of samples in all experimental groups were higher than the control group (gutta-percha and sealer). However, the superiority was not statistically significant except for teeth filled with a $5 \mathrm{~mm}$ MTA apical plug.

While this is the first study to compare the effect of MTA and CEM apical plugs on fracture resistance of teeth restored with cast metal posts, effect of the two materials on fracture resistance of teeth has been compared in other circumstances and controversial results were reported. Evren et al. (4) compared the fracture resistance of simulated immature human teeth using MTA, CEM, and Biodentine apical plugs, with fiber post and composite resin restoration. They reported no statistically significant difference of fracture resistance between MTA, CEM, and Biodentine, while all the three materials showed higher fracture resistance than control (no obturation) group. Sarraf et al. (24) compared the fracture resistance of immature bovine teeth filled with MTA, CEM, and Biodentine with no post-space preparation and placement. They reported that MTA and Biodentine showed superior results over CEM, and the fracture resistance was not different for CEM, gutta-percha and sealer, and control (dried cotton wool filling) groups. Milani et al. (8) also compared the fracture resistance of immature teeth filled with MTA, CEM, and MTA plus composite resin.

The results of the mentioned studies are not comparable to each other and to the present study, because of the great methodological variations regarding sample type (e.g. bovine/human teeth, premolars/incisors), sample preparations (e.g. immaturity simulation, root canal preparation and obturation techniques, post-space preparation, post systems), obturations (e.g. full canal/ apical plug, material thickness), coronal restorations (e.g composite resins, metal cores or crowns), testing machine (fatigue/static load, speed, angle) and several other factors. Hence, there is a need to standardize the methods, in order to perform fair comparisons and interpretations. 
The current study also showed no statistically significant difference of fracture resistance regarding the thickness of the apical plugs ( $2 \mathrm{~mm}$ or $5 \mathrm{~mm}$ ). Although several studies have been performed to compare the effect of using different thicknesses of apical plugs on root- end sealing ability (25-28), the studies assessing the effect of thickness on the apical of mechanical properties are rare. Madani et al. (28) compared the fracture resistance of simulated immature teeth, using 3 and $5 \mathrm{~mm}$ apical plugs of MTA and CEM. Teeth were then restored with glass fiber post and composite resin. As consistent with the current study, Madani et al. reported no statistically significant difference of fracture resistance between the experimental groups of different thickness. The only significant difference found in the present study was between group 1(5 mm MTA plug) and the control group, while there was no control group provided by Madani et al. The effect of thickness on surface micro-hardness of MTA and CEM has also been evaluated in several studies. A study performed by Tabrizizadeh et al (29) showed no statistical difference of surface micro-hardness between 4 and 8 mm MTA and CEM plugs. Login et al (30) also reported no statistic difference of surface micro-hardness between 4 and $6 \mathrm{~mm}$ MTA plugs, while $10 \mathrm{~mm}$ plugs were significantly harder that 4 and $6 \mathrm{~mm}$ plugs.

Root-end sealing ability, in addition to mechanical resistance and hardness, should be noticed while comparing different root-end filling materials and thicknesses. Adel et al. (25) who compared the root-end sealing ability of different thicknesses of MTA and CEM, reported a significantly higher sealing ability of 5 $\mathrm{mm}$ apical plugs compared to $3 \mathrm{~mm}$ apical plugs of both materials. Valois et al. (26) and Gosh et al (27), also reported a higher root-end sealing ability of $4 \mathrm{~mm}$ MTA plugs compared to lower thicknesses. Thus, decisions for clinical use of apical plugs should not be made only on the basis of mechanical properties. And comprehensive in-vitro and in-vivo studies of various factors influencing the clinical outcome of endodontics and prosthodontic treatment of immature teeth is required.

\section{Conclusions}

Within the limits of this study, the evidence indicated that placement of a $5 \mathrm{~mm}$ MTA apical plug increased the fracture resistance in simulated immature teeth which are restored with cast metal posts, compared to control group (gutta-percha and sealer). While the results were not as promising for a $2 \mathrm{~mm}$ MTA apical plug or either 2 or $5 \mathrm{~mm}$ CEM apical plug.

\section{Declarations}

\section{Ethics approval and consent to participate:}

Ethical approval for this study was obtained from the Ethics Committee of Golestan University of Medical Sciences (code: IR.GOUMS.REC.1397.191). All methods were carried out in accordance with relevant guidelines and regulations. The permission to utilize the teeth samples was granted by The Ethics Committee of Golestan University of Medical Sciences based on the recorded proposal (research code: 19-110580, ethics code: IR.GOUMS.REC.1397.191). The permission is also approved by Iran National Committee for Ethics in Biomedical research (https://ethics.research.ac.ir/IndexEn.php). 


\section{Consent for publication:}

Not applicable

\section{Availability of data and materials:}

The datasets used during the current study are available from the corresponding author on reasonable request.

\section{Competing interests:}

The authors declare that they have no competing interests.

\section{Funding:}

The study is funded by the Golestan University of Medical Sciences

\section{Authors' contributions:}

EG conceived, and designed the study, supervised and contributed to the endodontic procedures. AD carried out the major part of endodontic and prosthodontic procedures. LSh supervised and contributed to the prosthodontic procedures and contributed to the manuscript preparation. NB contributed to the data analysis, data interpretation and manuscript preparation. EA contributed to data interpretation and manuscript preparation. All authors read and approved the final manuscript.

\section{Acknowledgements:}

\section{Not applicable}

\section{References}

1. Tang $\mathrm{W}, \mathrm{Wu} Y$, Smales RJ. Identifying and reducing risks for potential fractures in endodontically treated teeth. Journal of endodontics. 2010 Apr 1;36(4):609-17.

2. Corsentino G, Pedullà E, Castelli L, Liguori M, Spicciarelli V, Martignoni M, Ferrari M, Grandini S. Influence of access cavity preparation and remaining tooth substance on fracture strength of endodontically treated teeth. Journal of endodontics. 2018 Sep 1;44(9):1416-21.

3. Bayram E, Bayram HM. Fracture resistance of immature teeth filled with mineral trioxide aggregate, bioaggregate, and biodentine. European journal of dentistry. 2016 Apr;10(2):220.

4. Evren OK, Altunsoy M, Tanriver M, Capar ID, Kalkan A, Gok T. Fracture resistance of simulated immature teeth after apexification with calcium silicate-based materials. European journal of dentistry. 2016 Apr;10(2):188.

5. Figueiredo FE, Martins-Filho PR, Faria-e-Silva AL. Do metal post-retained restorations result in more root fractures than fiber post-retained restorations? A systematic review and meta-analysis. Journal 
of endodontics. 2015 Mar 1;41(3):309-16.

6. Nagmode PS, Satpute AB, Patel AV, Ladhe PL. The effect of mineral trioxide aggregate on the periapical tissues after unintentional extrusion beyond the apical foramen. Case reports in dentistry. 2016 Jan 1;2016.

7. Abusrewil SM, McLean W, Scott JA. The use of Bioceramics as root-end filling materials in periradicular surgery: A literature review. The Saudi dental journal. 2018 Oct 1;30(4):273-82.

8. Milani AS, Rahimi S, Borna Z, Jafarabadi MA, Bahari M, Deljavan AS. Fracture resistance of immature teeth filled with mineral trioxide aggregate or calcium-enriched mixture cement: An ex vivo study. Dental research journal. 2012 May;9(3):299.

9. Andreasen JO, Munksgaard EC, Bakland LK. Comparison of fracture resistance in root canals of immature sheep teeth after filling with calcium hydroxide or MTA. Dental Traumatology. 2006 Jun;22(3):154-6.

10. Theodosopoulou JN, Chochlidakis KM. A systematic review of dowel (post) and core materials and systems. Journal of Prosthodontics: Implant, Esthetic and Reconstructive Dentistry. 2009 Aug;18(6):464-72.

11. Ricketts DN, Tait CM, Higgins AJ. Post and core systems, refinements to tooth preparation and cementation. British Dental Journal. 2005 May;198(9):533-41.

12. Borisova-Papancheva T, Stankova S, Georgieva S. Types of fiberposts and techniques used for restoration after endodontic treatment-literature review. InVarna Medical Forum 2017 Jun 20 (Vol. 6, No. 2, pp. 116-125).

13. Morgano SM, Milot P. Clinical success of cast metal posts and cores. The Journal of Prosthetic Dentistry. 1993 Jul 1;70(1):11-6.

14. Türker SA, Özçelik B, Yilmaz Z. Evaluation of the bond strength and fracture resistance of different post systems. J Contemp Dent Pract. 2015 Oct 1;16:788-93.

15. Goracci C, Ferrari M. Current perspectives on post systems: a literature review. Australian dental journal. 2011 Jun;56:77-83.

16. Schwartz RS, Robbins JW. Post placement and restoration of endodontically treated teeth: a literature review. Journal of endodontics. 2004 May 1;30(5):289-301.

17. Ahmed SN, Donovan TE, Ghuman T. Survey of dentists to determine contemporary use of endodontic posts. The Journal of prosthetic dentistry. 2017 May 1;117(5):642-5.

18. Girotto LP, Dotto L, Pereira GK, Bacchi A, Sarkis-Onofre R. Restorative preferences and choices of dentists and students for restoring endodontically treated teeth: A systematic review of survey studies. The Journal of Prosthetic Dentistry. 2020 Sep 25.

19. Ballal NV, Rao S, Yoo J, Ginjupalli K, Toledano M, Husain NA, Özcan M. Fracture resistance of teeth obturated with two different types of Mineral Trioxide Aggregate Cements. Brazilian Dental Science. 2020 Jun 30;23(3):9-p. 
20. Darak P, Likhitkar M, Goenka S, Kumar A, Madale P, Kelode A. Comparative evaluation of fracture resistance of simulated immature teeth and its effect on single visit apexification versus complete obturation using MTA and biodentine. Journal of Family Medicine and Primary Care. 2020 Apr 1;9(4):2011.

21. Boutsioukis C, Noula G, Lambrianidis T. Ex vivo study of the efficiency of two techniques for the removal of mineral trioxide aggregate used as a root canal filling material. Journal of endodontics. 2008 Oct 1;34(10):1239-42.

22. Moradi S, Disfani R, Ghazvini K, Lomee M. Sealing ability of orthograde MTA and CEM cement in apically resected roots using bacterial leakage method. Iranian endodontic journal. 2013;8(3):109.

23. Tabrizizade M, Asadi Y, Sooratgar A, Moradi S, Sooratgar H, Ayatollahi F. Sealing ability of mineral trioxide aggregate and calcium-enriched mixture cement as apical barriers with different obturation techniques. Iranian endodontic journal. 2014;9(4):261.

24. Sarraf $P$, Nekoofar MH, Sheykhrezae MS, Dummer PM. Fracture resistance of immature incisors following root filling with various bioactive endodontic cements using an experimental bovine tooth model. European journal of dentistry. 2019 May;13(2):156.

25. Adel M, Nima MM, Shivaie Kojoori S, Norooz Oliaie H, Naghavi N, Asgary S. Comparison of endodontic biomaterials as apical barriers in simulated open apices. ISRN dentistry. 2012;2012.

26. Valois CR, Costa Jr ED. Influence of the thickness of mineral trioxide aggregate on sealing ability of root-end fillings in vitro. Oral Surgery, Oral Medicine, Oral Pathology, Oral Radiology, and Endodontology. 2004 Jan 1;97(1):108-11.

27. Ghosh C, Kundu GK, Zahir S, Sarkar S, Bazmi BA, Kar S. A comparative evaluation of ideal apical sealing material for open apex single rooted permanent tooth: An in vitro study. SRM Journal of Research in Dental Sciences. 2015 Jul 1;6(3):145.

28. Madani ZS, Harandi A, Geraily E, Bijani A, Gharekhani S. Fracture strength of teeth restored with fiber post and apical plug. Caspian Journal of Dental Research. 2017 Sep 10;6(2):15-22.

29. Tabrizizadeh M, Dabbagh MM, Badrian H, Davoudi A. Microhardness Properties of Mineral Trioxide Aggregate and Calcium-enriched Mixture Cement Plugs at Different Setting Conditions. Journal of international oral health: JIOH. 2015 Sep;7(9):36.

30. Login CE. The influence of mineral trioxide aggregate (MTA) thickness on its microhardness properties-an in vitro study. 